University of Texas Rio Grande Valley

ScholarWorks @ UTRGV

Psychological Science Faculty Publications and

Presentations

$12-30-2021$

\title{
Patient perceptions of trauma-focused telemental health services using the Telehealth Satisfaction Questionnaire (TSQ)
}

Bianca T. Villalobos

The University of Texas Rio Grande Valley, bianca.villalobos@utrgv.edu

Aubrey R. Dueweke

Rosaura Orengo-Aguayo

Regan W. Stewart

Follow this and additional works at: https://scholarworks.utrgv.edu/psy_fac

Part of the Psychology Commons, and the Telemedicine Commons

\section{Recommended Citation}

Villalobos, B. T., Dueweke, A. R., Orengo-Aguayo, R., \& Stewart, R. W. (2021). Patient perceptions of trauma-focused telemental health services using the Telehealth Satisfaction Questionnaire (TSQ).

Psychological Services. https://doi.org/10.1037/ser0000605

This Article is brought to you for free and open access by the College of Liberal Arts at ScholarWorks @ UTRGV. It has been accepted for inclusion in Psychological Science Faculty Publications and Presentations by an authorized administrator of ScholarWorks @ UTRGV. For more information, please contact justin.white@utrgv.edu, william.flores01@utrgv.edu. 


\section{Patient Perceptions of Trauma-Focused Telemental Health Services Using the Telehealth Satisfaction Questionnaire (TSQ)}

Bianca T. Villalobos, $\mathrm{PhD}^{1}$, Aubrey R. Dueweke, $\mathrm{PhD}^{2}$, Rosaura Orengo-Aguayo, $\mathrm{PhD}^{2}$, and

$$
\text { Regan W. Stewart, } \mathrm{PhD}^{2}
$$

${ }^{1}$ Department of Psychological Science, The University of Texas Rio Grande Valley, Edinburg, TX

${ }^{2}$ Department of Psychiatry and Behavioral Sciences, Medical University of South Carolina, Charleston, SC

Corresponding author: Bianca T. Villalobos, Ph.D., Department of Psychological Sciences, The University of Texas Rio Grande Valley, 1201 W. University Dr., EIEAB 3.206, Edinburg, TX 78539. E-mail: bianca.villalobos@utrgv.edu

Funding: This work was supported by the Substance Abuse and Mental Health Services Administration, National Child Traumatic Stress Network, grant no. 1U79SM063224. The funding agency had no role in the study design, collection, analysis or interpretation of the data, writing the manuscript, or the decision to submit this paper for publication.

Declaration of Conflicting Interests: The authors declared no potential conflicts of interest with respect to the research, authorship, and/or publication of this article. 


\begin{abstract}
Telehealth services can address many barriers to traditional office-based mental health services. Few studies have assessed youth and caregiver perceptions of and satisfaction with traumafocused interventions delivered via telemental health. The current study presents data collected using the Telehealth Satisfaction Questionnaire (TSQ), which was developed to measure child and caregiver satisfaction with services, comfort with the telehealth equipment, and barriers to traditional office-based services. Thirteen clinicians delivered home- and school-based TraumaFocused Cognitive Behavioral Therapy (TF-CBT) via videoconferencing on tablets and computers to 60 child patients (71.7\% Latinx, 18.3\% Black, and 10.0\% non-Hispanic White). Patients and caregivers completed the TSQ at treatment discharge via telephone, videoconferencing, or in-person interviews. There was a high level of satisfaction among patients and caregivers receiving TF-CBT via telemental health. Furthermore, most youth and caregivers felt comfortable using the telehealth equipment from the outset of therapy, and all participants who were not initially comfortable using the equipment reported feeling more comfortable over time. The most common barriers to traditional office-based services were caregiver work schedule (57.7\%), distance to mental health clinic (55.8\%), and lack of transportation (44.2\%). Patients and caregivers expressed a preference for telemental health services if given the option between receiving therapy via videoconferencing versus going to an office-based clinic. Findings indicated telemental health treatment addressed barriers that would have otherwise prevented families from accessing office-based services. The Telehealth Satisfaction Questionnaire can be used to help clinics and providers assess patient and caregiver satisfaction with telehealth services in various settings.
\end{abstract}

Keywords: telehealth, satisfaction, barriers, cognitive behavior therapy, trauma 


\section{Impact Statement}

This study presents findings from the use of a new satisfaction survey that can be used by clinicians to assess satisfaction with telemental health services delivered via videoconferencing. High levels of satisfaction and comfort were demonstrated among youth and their caregivers who used tablets and laptops to connect to their clinicians for trauma-focused therapy. Many of the families in this study reported that they experienced barriers to traditional office-based services, which telehealth can help address. 


\section{Patient Perceptions of Trauma-Focused Telemental Health Services Using the Telehealth Satisfaction Questionnaire (TSQ)}

Barriers to mental health services can impede many individuals from obtaining needed treatment for several years after the onset of a mental health disorder (Wang et al., 2007; Wang, Berglund, et al., 2005). Even among those who are successful at making initial contact with mental health professionals, treatment dropout is high in community settings (Olfson et al., 2009; Wang, 2007). An abundance of research indicates that racial and ethnic minority communities and rural populations are most affected by disparities in access to mental health care (Cabassa et al., 2006; McGuire \& Miranda, 2008; U.S. Department of Health and Human Services, 2001; Wang, Lane, et al., 2005). Moreover, the underutilization of mental health services by these communities is compounded by the shortage of mental health providers in the workforce, as well as the recent worldwide COVID-19 pandemic that has limited the ability of many to obtain inperson specialty mental health services.

Although the use of telehealth as a medical service delivery model is not new, there has been an increasing reliance on technology and mobile health applications to provide psychotherapy treatment. The term telemental health specifically refers to the use of live, interactive videoconferencing for the provision of mental and behavioral health services to patients located at a distance (Cain et al., 2016). Telemental health technologies have the potential to address several of the aforementioned barriers to care (Wangelin et al., 2016; Kruse et al., 2017). For example, travel time, transportation costs, and missed work can be eliminated or reduced because patients can be seen from a variety of remote locations (i.e., home, school, work). Likewise, geographic coverage of service providers and dissemination of evidence-based and culturally-sensitive psychotherapy is enhanced, and stigma associated with going to a mental 
health facility is lessened. Indeed, telemental health treatment has been shown to be as effective as in-person care in randomized clinical trials (RCTs) for both children and adults with a range of presentations including posttraumatic stress disorder (PTSD; Morland et al., 2014; Strachan et al., 2012; Yuen et al., 2015; Ziemba et al., 2014), depression (Khatri et al., 2014; Nelson et al., 2003), anxiety disorders (Bouchard et al., 2004; Himle et al., 2012; Stubbings et al., 2013), and insomnia (Holmqvist et al., 2014).

Regarding patient acceptability of telemental health services, a systematic review of 14 studies indicated comparable rates of treatment satisfaction and therapeutic alliance between telemental health and in-person psychotherapeutic interventions (Jenkins-Guarnieri et al., 2015). However, the articles identified in the review focused exclusively on adults in treatment and RCTs have not yet examined whether youth satisfaction for telehealth is indeed comparable to face-to-face services. In addition, a majority of information on telemental health acceptability and feasibility with children and adolescents has primarily been developed in the field of telepsychiatry (for a review see Gloff et al., 2015). One study in youth telepsychiatry found parents were more satisfied with the treatment of their school-aged children compared to parents of adolescents (Myers et al., 2008). To our knowledge, no other studies have identified predictors of caregiver and youth satisfaction with telemental health. Thus, questions remain about the subjective satisfaction of youth and caregivers with child-focused psychotherapy interventions delivered via telemental health, especially for trauma-focused treatment where no research examining satisfaction exists.

Regarding traditional in-person services, a handful of studies have shown children and caregivers involved in Trauma-Focused Cognitive Behavioral Therapy (TF-CBT), the gold standard PTSD treatment for youth, are highly satisfied (Cohen et al., 2006; Lange et al., 2021; 
Salloum et al., 2016). However, the research on satisfaction with trauma-focused interventions using videoconferencing is lacking and limited to case studies (Shealy et al., 2015; Stewart et al., 2017; 2019). For example, case studies with three African American and four Hispanic families showed that culturally tailored TF-CBT delivered via telehealth was effective at reducing PTSD symptoms with high acceptability from families (Stewart et al., 2017; 2019). Although all the children in the case studies were seen via school-based telehealth, it is important to note that several caregivers were unable to attend sessions at the school due to their work schedules and transportation-related issues. These caregivers were loaned tablets in order to connect to therapists at home and stay involved in their child's treatment.

Caregivers are often regarded as supportive and essential players in many child interventions given their impact on child development and their ability to facilitate treatment attendance and adherence (Haine-Schlagel \& Walsh, 2015). Telehealth has the potential to increase both youth and caregiver involvement in TF-CBT, especially for families without a vehicle, who live hours away, or who are unable to take time off work during clinic hours. Moreover, telehealth allows the therapist to connect remotely and quite literally meet the child wherever they are, whether that be at home, school, or their hospital bed, making treatment more accessible. Of note, research has shown that compared to child-only treatment, caregiver involvement in TF-CBT results in greater depressive and behavioral symptom improvement among children and improved parenting practices among caregivers (Deblinger et al., 1996).

The telehealth modality also presents clinicians with the unique challenge of keeping youth engaged and attentive in treatment when no longer in the same room. Clinicians must adapt play-like activities and psychoeducational games to an online format that remains interactive and fun. Anecdotally, we have found that children under age seven have difficulty 
with sustained attention or appropriate use of the telehealth equipment. Clinicians using telehealth should consider the child's age, externalizing behaviors, and attention when evaluating their ability to stay seated for a session, damage equipment, or to stay within sight of a web camera. Furthermore, telehealth requires a more thorough assessment of safety issues and safety planning when working with youth presenting with suicidal behaviors since clinicians are no longer able to manage real-time crises in-person. Additional considerations for telehealth include ensuring privacy for sessions, modeling proper use of telehealth equipment, adapting worksheets and handouts for digital use, and troubleshooting technical issues (for additional recommendations, see Dueweke et al., 2020).

There is a clear need for further research on youth and caregiver satisfaction with childfocused telemental health services in the wake of trauma exposure, and in particular, more research is needed from the perspective of ethnic minority youth. In addition to being at greater risk of posttraumatic stress following trauma exposure (Andrews et al., 2019), Hispanic and non-Hispanic Black adolescents report higher rates of witnessing violence, loss, and polyvictimaztion compared to non-Hispanic White adolescents (López et al., 2017). Immigrant families in particular may be vulnerable to traumas during immigration which are not always captured by standard trauma assessments (de Arellano et al., 2018). Since 2014, the U.S. has experienced a surge in immigration from the Northern Triangle region of Central America by individuals displaced by civil unrest and fleeing community violence. This pattern of immigration has only been significantly reduced by the COVID-19 pandemic and associated border closures, but the pandemic itself has disproportionality impacted ethnic minority groups in the U.S. Given the current socio-political context in the U.S., trauma research with ethnic 
minority families is greatly needed to understand their need of, access to, and satisfaction with trauma-focused mental health services.

The purpose of the present study was to examine both child and caregiver perceptions of and satisfaction with telemental health services upon completion of TF-CBT. We also aimed to identify barriers to traditional office-based services. In order to do so, a new telehealth satisfaction measure was developed: the Telehealth Satisfaction Questionnaire (TSQ). Of note, we designed the TSQ so that it could be used to assess telehealth services for a variety of clinical presentations and service programs.

\section{Method}

\section{Participants}

Participants were 60 youth who completed a course of outpatient TF-CBT via telehealth and their caregivers. Youth were primarily referred to treatment through school staff, child advocacy centers, and self-referrals. All youth met criteria for PTSD ( $n=46 ; 76.7 \%)$, an adjustment disorder $(n=8 ; 13.3 \%)$, or other trauma- and stressor-related disorder $(n=6 ; 10.0 \%)$

at the time of intake, according to the Diagnostic and Statistical Manual of Mental Disorders, $5^{\text {th }}$ edition (DSM-5; American Psychiatric Association, 2013). Posttraumatic stress symptoms were assessed using the University of California Los Angeles PTSD Reaction Index (UCLA PTSD RI; Steinberg et al., 2004) or the Child PTSD Symptom Scale for DSM-5 (CPSS-5; Foa et al., 2018). Youth were enrolled in treatment if they were between the ages of 7 and 18 and reported experiencing at least one traumatic event with significant symptoms of posttraumatic stress. To receive telehealth services, families had to report at least one barrier to accessing office-based treatment (e.g., caregiver work schedule, rural location). Youth were not seen via telehealth if 
they endorsed current significant suicidal ideation, exhibited serious externalizing behaviors that would endanger themselves or the telehealth equipment, or were under the age of seven.

\section{Telemental Health Services}

All youth involved in the present study were seen through the Telehealth Outreach Program (TOP) at the Medical University of South Carolina. The TOP clinic was developed to deliver evidence-based trauma treatment (i.e., TF-CBT) to underserved children and adolescents across South Carolina and involves the use of telehealth equipment (i.e., cellular data-enabled tablets and laptop computers) and videoconferencing software to conduct teletherapy sessions at homes or schools. TF-CBT is an empirically validated, manualized treatment delivered over 1224 weekly sessions and includes the following components: (a) psychoeducation, (b) parenting skills, (c) relaxation skills, (d) affective modulation skills, (e) cognitive processing skills, (f) trauma narration and processing, (g) in vivo mastery of trauma reminders, (h) conjoint childparent sessions, and (i) enhancing safety. Efficacy for TF-CBT in reducing posttraumatic stress symptoms among youth ages 3-18 has been established through several RCTs across a range of populations and treatment settings (Cohen et al., 2017). Preliminary data from a TOP open pilot trial suggest it is effective when delivered via telehealth (Stewart et al., 2020). Youth in the present study experienced clinically meaningful declines in PTSD symptoms from pre- to posttreatment, with large effect sizes for both child- and caregiver-reported symptom reduction (Cohen's $d$ for child-reported PTSD symptoms via UCLA PTSD RI = 2.11; Cohen's $d$ for childreported PTSD symptoms via CPSS-5 = 1.02; Cohen's $d$ for caregiver-reported PTSD symptoms via UCLA PTSD RI = 1.52; Cohen's $d$ for caregiver-reported PTSD symptoms via CPSS-5 = $1.01)$. 
When caregivers are involved in TF-CBT, therapists begin with weekly individual sessions with the child and then hold a session afterwards with the caregiver in a parallel review of the same treatment component. Conjoint sessions do not begin until the last phase of treatment when children share a trauma narrative with the caregiver. Up until then, individual sessions with the caregiver focus on building effective parenting skills, coping with and processing their own reactions to the trauma, and preparing them to listen to the trauma narrative in the conjoint sessions. Total session time split between the child and caregiver can last between 45-90 minutes.

Treatment was provided by one bilingual (English-Spanish) licensed clinical psychologist, four bilingual (English-Spanish) postdoctoral fellows with $\mathrm{PhDs}$ in clinical psychology, and eight predoctoral clinical psychology interns (one bilingual English-Spanish speaker and seven monolingual English speakers). One Spanish-speaking patient received services through use of an interpreter, who was included in sessions via a three-way videoconference call. Therapists were all trained in TF-CBT and received weekly clinical supervision from a licensed clinical psychologist.

Intake procedures included a semi-structured clinical interview conducted separately with the youth and caregiver, as well as the completion of self-report questionnaires. The initial intake evaluation was conducted in person or via telehealth for those families who lived more than 30 minutes away from the trauma clinic. In most cases, the intake clinician was also the treating provider depending on patient needs and clinician availability. Prior to treatment, clinicians visited schools and families in person to demonstrate proper use of telehealth equipment, assist with setting up the videoconferencing software, and test internet connections to ensure sufficient bandwidth. In addition, clinicians reviewed ideal expectations for the physical environment in 
which treatment should occur (i.e., quiet and private space, minimization of distractions) and developed a safety protocol with caregivers or school staff to take action if the child were to express suicidal ideation or leave the view of the webcam (see Stewart et al., 2020 for additional details). During treatment, clinicians frequently used the videoconferencing software's screen sharing function to complete interactive worksheets and games and keep youth actively engaged (Dueweke et al., 2020).

\section{Measure Development}

Data on satisfaction were collected using the TSQ, a new measure developed by the authors (see Appendix A and B). The TSQ was developed through a review of published instruments and includes adapted items from the following satisfaction questionnaires: the Service Satisfaction Questionnaire (Kopel et al., 2001), the Mobile Telehealth (mTH) Patient Satisfaction Questionnaire (Whealin et al., 2017), and the Satisfaction with Teledermatology Questionnaire (Hicks et al., 2003). Additional questions were added to further assess perceptions of cultural sensitivity of the clinician, concerns about privacy, change in comfort using the telehealth equipment over time, and barriers to traditional office-based services. The measure is available in English and Spanish ${ }^{1}$ and can be delivered as an interview in-person, via telehealth, or over the phone with patients and caregivers.

Child and caregiver report versions of the TSQ were created with modifications made to facilitate responses from children (i.e., response options were reduced and wording of some items was simplified). The child report measure (for children $\geq 11$ years old) includes a total of 17 items. Thirteen items use a 4-point Likert scale ranging from 1 (Disagree A Lot) to 4 (Agree A Lot) to indicate agreement with statements about satisfaction, ease of use, alliance, and

\footnotetext{
${ }^{1}$ The Spanish version of the TSQ is available from the authors upon request.
} 
preference for telehealth over in-person treatment. Cronbach's alpha for these 13 items was 0.80 in the present sample, which is indicative of good internal consistency. An additional "Yes/No" item regarding comfort using telehealth equipment at the time of the first visit is included. If youth indicate they were not comfortable with using telehealth equipment at the initiation of treatment, a series of follow-up questions ask what their concerns were, whether their comfort increased over time, and what changed to make them more comfortable. Lastly, youth are asked three open-ended qualitative items about what they liked about the telehealth program, recommendations for improvement, and any additional feedback.

The TSQ caregiver report measure (administered to all caregivers, regardless of the child's age) contains a total of 22 items to be completed by a caregiver involved in the child's treatment (i.e., who met with the child's clinician for caregiver and/or family sessions). Much like the child report version, the caregiver report measure contains 16 items that utilize a 5-point Likert scale ranging from 1 (Strongly Disagree) to 5 (Strongly Agree), questions regarding comfort using telehealth equipment at the initiation of treatment and over time, and open-ended items at the end of the measure to provide feedback. The caregiver report measure also includes a checklist of barriers which may have prevented the child from being seen in a traditional office-based setting. Caregivers also report their distance (in miles and/or minutes) from the nearest office-based mental health service. The 16 Likert scale items of the TSQ caregiver report measure demonstrated good internal consistency in this sample (Cronbach's alpha $=0.89$ ).

\section{Procedure}

Data for the present study were collected over a 43-month period between November 2017 and May 2021. The TSQ interview was conducted after post-treatment measures were completed by patients and caregivers as part of standard clinical operations. The TSQ was 
administered to caregivers whenever possible, though some youth complete treatment without the involvement of a caregiver and the TSQ was not given to caregivers in these instances. Importantly, the TSQ was administered as an interview conducted by someone other than the treating provider (i.e., staff member or another clinician). TSQ interviews were conducted over the phone, via videoconferencing, or in-person, and took between 5 and 15 minutes to complete. To extract data for the present study, we used closed chart review of patients who received services through the TOP clinic (which received Institutional Review Board approval).

\section{Results}

\section{Demographics}

Child participants ranged in age from 7-18 years $(M=12.95, S D=3.22)$ and were primarily female $(n=42,70.0 \%)$. Almost $72 \%(n=43)$ of the child participants identified as Latinx, while $18.3 \%(n=11)$ identified as Black and $10.0 \%(n=6)$ identified as non-Latinx White. Roughly $63 \%$ of the youth spoke English as their primary language, while $36.7 \%$ spoke Spanish as their primary language. Seventy percent of the caregivers spoke Spanish as their primary language, while $30.0 \%$ spoke English as their primary language. Caregivers participating in treatment were mostly mothers $(n=41 ; 80.4 \%)$, followed by fathers $(n=4$; $7.8 \%)$, foster parents $(n=3 ; 5.9 \%)$, aunts $(n=2 ; 3.9 \%)$, and one grandmother $(n=1 ; 2.0 \%)$. Children received services at their home $(n=28 ; 46.7 \%)$, school $(n=10 ; 16.7 \%)$, or both $(n=$ $22 ; 36.7 \%)$ using cellular data-enabled tablets $(n=38 ; 63.3 \%)$ and laptop computers $(n=38$; $63.3 \%)$. Children attended an average of 17.18 therapy sessions $(S D=6.13$, range 6-45) and caregivers attended an average of 9.92 sessions $(S D=5.99$, range $0-28)$. Of the 60 families surveyed in the present study, 35 completed both a child and caregiver report version of the TSQ, 
16 completed only a caregiver report because the child was under the age of 11 , and 9 completed only a child report because there was no caregiver involved in treatment.

\section{Satisfaction with Telehealth Services and Comfort Using Telehealth Equipment}

Child patients reported being highly satisfied with telehealth services $(M=3.84, S D=$ $0.23)$, as did their caregivers $(M=4.70, S D=0.35)$. Satisfaction ratings were high in generalaround $98 \%$ of all the responses to items on both the child and caregiver report versions of the TSQ were either “Agree/Agree a little" or "Strongly agree/Agree a lot." Tables 1 and 2 summarize satisfaction ratings for children and caregivers, respectively.

Satisfaction ratings did not differ by patient gender, ethnicity, or language. While TSQ child report scores were uncorrelated with patient age $(r=.05)$, there was a significant negative correlation between TSQ caregiver report scores and patient age $(r=-.29)$. Satisfaction ratings did not differ based on location of services, nor were they significantly associated with PSTD symptom change. Finally, satisfaction ratings were uncorrelated with the number of barriers reported or distance from the nearest mental health clinic.

Of note, all child and caregiver participants reported they felt comfortable interacting with their therapist using the telehealth equipment, had the same level of connection via telehealth as they did for in-person visits, and felt the therapist cared about the child and respected their family's values and beliefs. Ninety-three percent of youth and $100 \%$ of caregivers indicated telehealth visits were just as good as seeing therapists in-person. Almost all caregivers $(98.0 \%)$ and youth $(95.5 \%)$ indicated they would use telehealth if in need of services again and a similar proportion (96.1\% of caregivers and $95.5 \%$ of youth) preferred to use telehealth services rather than travel to our clinic to see a provider in person. In terms of quality of care, $98.0 \%$ of caregivers indicated they agreed or strongly agreed that their child received high quality 
telehealth services through the TOP clinic. Regarding increasing access to care, $84.3 \%$ of caregivers indicated that their child was only able to attend therapy sessions because they were offered via telehealth.

All youth indicated that the telehealth equipment was easy to use compared to $94.0 \%$ of caregivers. Additionally, $84.1 \%$ of youth and $88.0 \%$ of caregivers felt comfortable using the telehealth equipment from the outset of therapy, and all participants who were not initially comfortable using the equipment reported feeling more comfortable with the equipment over time. None of the participants reported concerns about privacy during telehealth sessions.

\section{Barriers to Office-Based Services}

Over $82 \%$ of families experienced barriers that would have prevented them from seeing a clinician face-to-face in office-based care. The most commonly reported barriers included caregiver work schedule (57.7\%), distance to an office-based mental health clinic $(55.8 \%)$, lack of transportation (44.2\%), and not being sure where to go or what services were available nearby (36.5\%). Other barriers included the need for childcare (34.6\%), cost of services $(34.6 \%)$, lack of insurance (34.6\%), and concern about stigma (17.3\%). Caregivers reported that they would have had to travel between 5 and 89 miles $(M=27.67, S D=27.39)$ and between 15 and 90 minutes $(M=36.64, S D=21.89)$ to get to the closest office-based mental health services.

\section{Qualitative Responses}

Child and caregiver responses to open-ended questions also demonstrated high levels of satisfaction with the telehealth services. For example, in response to the question, "What was the best part about the telehealth therapy?", one youth said, "That we didn't have to go downtown. The therapist was really supportive even though you aren't seeing them face-to-face." Similarly, one caregiver said, "That my daughter received treatment in the comfort of her own home, it was 
very private, a safe space for her." When asked if they had any additional comments about the telehealth program, one caregiver said, "My children liked doing therapy on the tablet better than in person. When they had to go to the clinic, they said it was boring to travel there. The therapist worked very well with them."

\section{Discussion}

While patient satisfaction with telehealth services has been evaluated in some domains (e.g., telemedicine, telepsychiatry), fewer studies have obtained patient perspectives about telemental health services for trauma, and to our knowledge only one has solicited the subjective perceptions of both children and caregivers in TF-CBT (Lange et al., 2021). Results of the present study demonstrated high satisfaction ratings from children and caregivers receiving trauma-focused telemental health services. Consistent with previous research in telepsychiatry, caregivers of older youth were slightly less satisfied with services than caregivers of younger children (i.e., Myers et al., 2008). It is possible that caregivers of older youth expected more transparency regarding disclosures made during their teen's one-on-one sessions with the clinician or were expecting more comprehensive services than the trauma clinic could provide. The majority of both children and caregivers reported they preferred using telehealth services over coming to a clinic for in-person services. By assessing identified barriers to office-based services and inquiring about the family's distance to traditional mental health services, we confirmed the need for telehealth services exists not only for those living in rural areas hours away, but also for those who lived only minutes away in urban underserved areas near our clinic. Similarly, lack of transportation and distance to a mental health clinic were some of the most commonly reported barriers to office-based services, suggesting that the majority of families would not have been able to attend sessions if services were office-based. 
Furthermore, families indicated they were still able to build rapport with clinicians and felt comfortable interacting with them via videoconferencing. The ability to maintain a strong therapeutic alliance is especially important when conducting trauma-focused treatment given the need to help families process and discuss oftentimes sensitive, violent, and extremely stressful events during therapy sessions. In addition, clinicians facilitate gradual exposure over the course of TF-CBT and rely on patient verbal and non-verbal cues of distress to proceed with increasingly trauma-specific content. It appears the clinicians were successful at navigating these challenging tasks via telehealth. In addition, all children and caregivers reported feeling as connected to their clinicians as if they were seeing them in-person and agreed that their information was kept private during sessions. Ultimately, it appears rapport was not significantly hindered by the use of telehealth from the perspective of children and caregivers. Future studies can confirm this by directly measuring therapeutic alliance and assessing its relation to telehealth satisfaction scores for youth treatments. Moreover, RCTs are needed to establish that youth telehealth satisfaction ratings are comparable to face-to-face treatment.

This study is not without limitations. The psychometric properties of the TSQ have yet to be established and require continued data collection for proper analyses given our small sample size. Additionally, children and caregivers were not asked about their perceptions of telehealth before they initiated treatment. Relatedly, those who dropped out prematurely from treatment did not complete satisfaction surveys. However, Lange et al. (2021) found parental satisfaction was higher for treatment completers than non-completers for in-person TF-CBT. Future studies should also conduct completer analyses for youth satisfaction ratings of TF-CBT via telehealth. Our telehealth program's attrition rate of $11.4 \%$ (Stewart et al., 2020), which is lower than many in-person treatment studies for TF-CBT (Wamser-Nanney \& Steinzor, 2016), could be a sign of 
satisfaction with services. Determining caregiver level of comfort with and experience using technology at the beginning of treatment would allow clinicians to adapt their approach and enlist the help of the youth or other family member/school staff to assist those who did not feel confident in their ability to initiate therapy sessions with the laptop or tablet. Having some measure pre-post would help determine actual change in level of comfort rather than relying on recall. Lastly, we had relatively few child-caregiver pairs and, overall, little variability in responses to determine possible group differences based on patient demographic characteristics and symptom improvement. Although we found no relation between telehealth satisfaction and symptom improvement for TF-CBT, future studies should replicate this analysis with larger samples. Lack of variability may also be due to the mode of administration. One might expect an interview with a clinic staff member to elicit more positive responses compared to a questionnaire that families complete on their own. Alternatively, written questionnaires would not be preferable for clients with low literacy. Thus, the results of this study should be considered with measurement biases in mind since timing, positive framing of items, and mode of administration can impact satisfaction survey responses (Saldivar et al., 2019).

To ensure completion of the TSQ, we recommend administering it at the time of the last session. We found this method increased the percentage of responses in comparison to contacting children and caregivers at a later time to complete the survey. This recommendation also aligns with previous research that found patient response rates are lower and satisfaction scores are poorer the more time has passed since treatment discharge (Bjertnaes, 2012). Lower response rates and unstable responses to satisfaction surveys over time also have broader implications for clinics engaged in program evaluation/quality improvement efforts to fund and expand telehealth services. Future studies should further evaluate the utility and validity of the TSQ to examine the 
acceptability of a telehealth service delivery modality for trauma treatment for youth. It will be important to examine differences in the level of comfort utilizing telehealth equipment among child and caregiver dyads as this may have a direct impact on whether telehealth sessions are successful and patients remain engaged in services. Potential differences in perceptions of telehealth among different racial and ethnic minority groups will need to be explored, as well as variability in perceptions by age and socioeconomic status of patients and their caregivers. Intersectionality should also be considered, as multiple oppressed identities can compound the negative effects of discrimination and increase barriers to treatment. For example, a youth who identifies as Latinx, undocumented, Spanish-speaking, transgender, and living in rural South Carolina can experience harassment and physical violence due to their immigrant and legal status, language, culture, and sexual identity. This youth may also face challenges accessing services and have a mistrust of professional service systems due to these same identities and their geographical location.

Furthermore, it will be important to examine ways in which telehealth technology decreases barriers in access to mental health care and reduces long-term costs associated with untreated mental health conditions. These data will be crucial in advocating for parity in payment on behalf of insurance companies for mental health services delivered via telehealth. Assessing patient satisfaction can provide clinicians with evidence to determine whether telehealth is a viable alternative to reduce barriers in access to care for their patients, especially during public health crises that restrict in-person visits. For example, since the start of the COVID-19 pandemic many clinicians have transitioned to the use of telemental health to continue seeing their patients and to address the needs of underserved populations disproportionately impacted by the virus. For clinics seeking to improve the quality of their service provision, administering 
satisfaction surveys that are both quantitative and qualitative in nature can provide much needed insight, especially from youth who are often considered advanced in their ability to use technology. In our experience, we have found that the use of telehealth for psychotherapy is distinct from their daily use of social media, texting, and video chats, and requires orientation to therapy etiquette. Finally, the TSQ was designed to be used broadly as individual items do not refer specifically to trauma-focused services or particular settings for treatment (school, clinic, inpatient, primary care, etc.). Moreover, the TSQ demonstrated good internal consistency for child and caregiver versions and is available in English and Spanish. Although it is administered as an interview, it can be completed in as little as five minutes by individuals with at least a $7^{\text {th }}$ grade reading level. Future studies should consider its use for assessing satisfaction with and acceptability of other telemental health treatments for additional populations not explored in the present study. 


\section{References}

American Psychiatric Association. (2013). Diagnostic and Statistical Manual of Mental

Disorders (5th ed.). American Psychiatric Publishing.

https://doi.org/10.1176/appi.books.9780890425596

Andrews, A. R., Jobe-Shields, L., López, C. M., Metzger, I. W., de Arellano, M. A. R., Saunders, B., \& Kilpatrick, D. (2015). Polyvictimization, income, and ethnic differences in trauma-related mental health during adolescence. Social Psychiatry and Psychiatric Epidemiology, 50(8), 1223-1234. https://doi.org/10.1007/s00127-015-1077-3

Bjertnaes, O. A. (2012). The association between survey timing and patient-reported experiences with hospitals: results of a national postal survey. BMC Medical Research Methodology, 12(1), 1-6. https://doi.org/10.1186/1471-2288-12-13

Bouchard, S., Paquin, B., Payeur, R., Allard, M., Rivard, V., Fournier, T., Renaud, P., \& Lapierre, J. (2004). Delivering cognitive-behavior therapy for panic disorder with agoraphobia in videoconference. Telemedicine Journal and e-Health, 10(1), 13-25. https://doi.org/10.1089/153056204773644535

Cabassa, L. J., Zayas, L. H., \& Hansen, M. C. (2006). Latino adults' access to mental health care: A review of epidemiological studies. Administration and Policy in Mental Health and Mental Health Services Research, 33(3), 316-330. https://doi.org/10.1007/s10488-006$\underline{0040-8}$

Cain, S., Nelson, E.-L., \& Myers, K. (2016). Telemental Health. In M. K. Dulcan (Ed.), Dulcan's Textbook of Child and Adolescent Psychiatry (2nd ed., pp. 669-688). American Psychiatric Association Publishing. https://doi.org/10.1176/appi.books.9781615370306.md33 
Cohen, J. A., Mannarino, A. P., \& Deblinger, E. (2017). Treating trauma and traumatic grief in children and adolescents (2nd ed.). Guilford Press.

Cohen, J. A., Mannarino, A. P., \& Staron, V. R. (2006). A pilot study of modified cognitivebehavioral therapy for childhood traumatic grief (CBT-CTG). Journal of the American Academy of Child \& Adolescent Psychiatry, 45(12), 1465-1473. https://doi.org/10.1097/01.chi.0000237705.43260.2c

de Arellano, M. A., Andrews III, A. R., Reid-Quiñones, K., Vasquez, D., Doherty, L. S., Danielson, C. K., \& Rheingold, A. (2018). Immigration trauma among Hispanic youth: Missed by trauma assessments and predictive of depression and PTSD symptoms. Journal of Latina/o Psychology, 6(3), 159-174. https://doi.org/10.1037/lat0000090

Deblinger, E., Lippmann, J., \& Steer, R. (1996). Sexually abused children suffering posttraumatic stress symptoms: Initial treatment outcome findings. Child Maltreatment, 1(4), 310-321. https://doi.org/10.1177/1077559596001004003

Dueweke, A. R., Wallace, M. M., Nicasio, A. V., Villalobos, B. T., Hernandez Rodriguez, J., \& Stewart, R. W. (2020). Resources and recommendations for engaging children and adolescents in telemental health interventions during COVID-19 and beyond. Behavior Therapist, 43(5), 137-145. http://www.abct.org/docs/PastIssue/43n5.pdf

Foa, E. B., Asnaani, A., Zang, Y., Capaldi, S., \& Yeh, R. (2018). Psychometrics of the Child PTSD Symptom Scale for DSM-5 for Trauma-Exposed Children and Adolescents. Journal of Clinical Child \& Adolescent Psychology, 47(1), 38-46. https://doi.org/10.1080/15374416.2017.1350962 
Gloff, N. E., LeNoue, S. R., Novins, D. K., \& Myers, K. (2015). Telemental health for children and adolescents. International Review of Psychiatry, 27(6), 513-524. https://doi.org/10.3109/09540261.2015.1086322

Haine-Schlagel, R., \& Walsh, N. E. (2015). A review of parent participation engagement in child and family mental health treatment. Clinical Child and Family Psychology Review, 18(2), 133-150. https://doi.org/10.1007/s10567-015-0182-X

Hicks, L. L., Boles, K. E., Hudson, S., Kling, B., Tracy, J., Mitchell, J., \& Webb, W. (2003). Patient satisfaction with teledermatology services. Journal of Telemedicine and Telecare, 9(1), 42-45. https://doi.org/10.1258/135763303321159684

Himle, M. B., Freitag, M., Walther, M., Franklin, S. A., Ely, L., \& Woods, D. W. (2012). A randomized pilot trial comparing videoconference versus face-to-face delivery of behavior therapy for childhood tic disorders. Behaviour Research and Therapy, 50(9), 565-570. https://doi.org/10.1016/j.brat.2012.05.009

Holmqvist, M., Vincent, N., \& Walsh, K. (2014). Web- vs. telehealth-based delivery of cognitive behavioral therapy for insomnia: a randomized controlled trial. Sleep Medicine, 15(2), 187-195. https://doi.org/10.1016/j.sleep.2013.10.013

Jenkins-Guarnieri, M. A., Pruitt, L. D., Luxton, D. D., \& Johnson, K. (2015). Patient Perceptions of Telemental Health: Systematic Review of Direct Comparisons to In-Person Psychotherapeutic Treatments. Telemedicine and e-Health, 21(8), 652-660. https://doi.org/10.1089/tmj.2014.0165

Khatri, N., Marziali, E., Tchernikov, I., \& Shepherd, N. (2014). Comparing telehealth-based and clinic-based group cognitive behavioral therapy for adults with depression and anxiety: a 
pilot study. Clinical Interventions in Aging, 9, 765-770.

https://doi.org/10.2147/CIA.S57832

Kopel, H., Nunn, K., \& Dossetor, D. (2001). Evaluating satisfaction with a child and adolescent psychological telemedicine outreach service. Journal of Telemedicine and Telecare, 7 Suppl 2, 35-40. https://doi.org/10.1258/1357633011937074

Kruse, C. S., Krowski, N., Rodriguez, B., Tran, L., Vela, J., \& Brooks, M. (2017). Telehealth and patient satisfaction: a systematic review and narrative analysis. BMJ Open, 7(8), e016242. https://doi.org/10.1136/bmjopen-2017-016242

Lange, B. C., Loser, A., \& Lang, J. M. (2021). Caregiver satisfaction with their child's traumafocused cognitive behavioral therapy. Psychological Trauma: Theory, Research, Practice, and Policy, 13(4), 476-485. https://doi.org/10.1037/tra0000834

McGuire, T. G., \& Miranda, J. (2008). New evidence regarding racial and ethnic disparities in mental health: Policy implications. Health Affairs, 27(2), 393-403. https://doi.org/10.1377/hlthaff.27.2.393

Morland, L. A., Mackintosh, M. A., Greene, C. J., Rosen, C. S., Chard, K. M., Resick, P., \& Frueh, B. C. (2014). Cognitive processing therapy for posttraumatic stress disorder delivered to rural veterans via telemental health: a randomized noninferiority clinical trial. Journal of Clinical Psychiatry, 75(5), 470-476. https://doi.org/10.4088/JCP.13m08842

Myers, K. M., Valentine, J. M., \& Melzer, S. M. (2008). Child and adolescent telepsychiatry: utilization and satisfaction. Telemedicine and e-Health, 14(2), 131-137. https://doi.org/10.1089/tmj.2007.0035 
Nelson, E. L., Barnard, M., \& Cain, S. (2003). Treating childhood depression over videoconferencing. Telemedicine Journal and e-Health, 9(1), 49-55. https://doi.org/10.1089/153056203763317648

Olfson, M., Mojtabai, R., Sampson, N. A., Hwang, I., Druss, B., Wang, P. S., Wells, K. B., Pincus, H. A., \& Kessler, R. C. (2009). Dropout from outpatient mental health care in the United States. Psychiatric Services, 60(7), 898-907. https://doi.org/10.1176/appi.ps.60.7.898

Saldivar, B., Carter, C., Filipp, S. L., Gurka, M. J., \& Davis, M. K. (2019). Patient Satisfaction Surveys in the Outpatient Clinic Setting: The Variability of Response With Positively or Negatively Toned Questions. INQUIRY: The Journal of Health Care Organization, Provision, and Financing, 56, Advanced Online Publication. https://doi.org/10.1177/0046958019875554

Salloum, A., Wang, W., Robst, J., Murphy, T. K., Scheeringa, M. S., Cohen, J. A., \& Storch, E. A. (2016). Stepped care versus standard trauma-focused cognitive behavioral therapy for young children. Journal of Child Psychology and Psychiatry, 57(5), 614-622. https://doi.org/10.1111/jcpp.12471

Shealy, K. M., Davidson, T. M., Jones, A. M., Lopez, C. M., \& de Arellano, M. A. (2015). Delivering an evidence-based mental health treatment to underserved populations using telemedicine: The case of a trauma-affected adolescent in a rural setting. Cognitive and Behavioral Practice, 22(3), 331-344. https://doi.org/10.1016/j.cbpra.2014.04.007

Steinberg, A. M., Brymer, M. J., Decker, K. B., \& Pynoos, R. S. (2004). The University of California at Los Angeles Post-traumatic Stress Disorder Reaction Index. Current Psychiatry Reports, 6(2), 96-100. https://doi.org/10.1007/s11920-004-0048-2 
Stewart, R. W., Orengo-Aguayo, R. E., Gilmore, A. K., \& de Arellano, M. (2017). Addressing barriers to care among Hispanic youth: Telehealth delivery of trauma-focused cognitive behavioral therapy. The Behavior Therapist, 40(3), 112-118.

Stewart, R. W., Orengo-Aguayo, R., Wallace, M., Metzger, I. W., \& Rheingold, A. A. (2019). Leveraging technology and cultural adaptations to increase access and engagement among trauma-exposed african american youth: Exploratory study of school-based telehealth delivery of trauma-focused cognitive behavioral therapy. Journal of Interpersonal Violence. Advance online publication. https://doi.org/10.1177/0886260519831380

Stewart, R. W., Orengo-Aguayo, R., Young, J., Wallace, M. M., Cohen, J. A., Mannarino, A. P., \& de Arellano, M. A. (2020). Feasibility and effectiveness of a telehealth service delivery model for treating childhood posttraumatic stress: A community-based, open pilot trial of trauma-focused cognitive-behavioral therapy. Journal of Psychotherapy Integration, 30(2), 274-289. http://dx.doi.org/10.1037/int0000225

Strachan, M., Gros, D. F., Yuen, E., Ruggiero, K. J., Foa, E. B., \& Acierno, R. (2012). Homebased telehealth to deliver evidence-based psychotherapy in veterans with PTSD. Contemporary Clinical Trials, 33(2), 402-409. https://doi.org/10.1016/j.cct.2011.11.007

Stubbings, D. R., Rees, C. S., Roberts, L. D., \& Kane, R. T. (2013). Comparing in-person to videoconference-based cognitive behavioral therapy for mood and anxiety disorders: randomized controlled trial. Journal of Medical Internet Research, 15(11), e258. https://doi.org/10.2196/jmir.2564

U.S. Department of Health and Human Services. (2001). Mental Health: Culture, Race, and Ethnicity-A Supplement to Mental Health: A Report of the Surgeon General. Substance 
Abuse and Mental Health Services Administration.

https://www.ncbi.nlm.nih.gov/books/NBK44243/

Wamser-Nanney, R., \& Steinzor, C. E. (2017). Factors related to attrition from trauma-focused cognitive behavioral therapy. Child Abuse \& Neglect, 66, 73-83. https://doi.org/10.1016/j.chiabu.2016.11.031

Wang, J. (2007). Mental health treatment dropout and its correlates in a general population sample. Medical Care, 45(3), 224-229. https://doi.org/10.1097/01.mlr.0000244506.86885.a5

Wang, P. S., Angermeyer, M., Borges, G., Bruffaerts, R., Tat Chiu, W., de Girolamo, G., Fayyad, J., Gureje, O., Haro, J. M., Huang, Y., Kessler, R. C., Kovess, V., Levinson, D., Nakane, Y., Oakley Brown, M. A., Ormel, J. H., Posada-Villa, J., Aguilar-Gaxiola, S., Alonso, J., ... Ustün, T. B. (2007). Delay and failure in treatment seeking after first onset of mental disorders in the World Health Organization's World Mental Health Survey Initiative. World Psychiatry, 6(3), 177-185. https://www.ncbi.nlm.nih.gov/pmc/articles/PMC2174579/

Wang, P. S., Berglund, P., Olfson, M., Pincus, H. A., Wells, K. B., \& Kessler, R. C. (2005). Failure and delay in initial treatment contact after first onset of mental disorders in the National Comorbidity Survey Replication. Archives of General Psychiatry, 62(6), 603613. https://doi.org/10.1001/archpsyc.62.6.603

Wang, P. S., Lane, M., Olfson, M., Pincus, H. A., Wells, K. B., \& Kessler, R. C. (2005). Twelvemonth use of mental health services in the United States: results from the National Comorbidity Survey Replication. Archives of General Psychiatry, 62(6), 629-640. https://doi.org/10.1001/archpsyc.62.6.629 
Wangelin, B. C., Szafranski, D. D., \& Gros, D. F. (2016). Telehealth Technologies in EvidenceBased Psychotherapy. In J. K. Luiselli \& A. J. Fischer (Eds.), Computer-Assisted and Web-Based Innovations in Psychology, Special Education, and Health (pp. 119-140). Academic Press. https://doi.org/10.1016/b978-0-12-802075-3.00005-X

Whealin, J. M., King, L., Shore, P., \& Spira, J. L. (2017). Diverse veterans' pre- and postintervention perceptions of home telemental health for posttraumatic stress disorder delivered via tablet. International Journal of Psychiatry in Medicine, 52(1), 3-20. https://doi.org/10.1177/0091217417703291

Yuen, E. K., Gros, D. F., Price, M., Zeigler, S., Tuerk, P. W., Foa, E. B., \& Acierno, R. (2015). Randomized Controlled Trial of Home-Based Telehealth Versus In-Person Prolonged Exposure for Combat-Related PTSD in Veterans: Preliminary Results. Journal of Clinical Psychology, 71(6), 500-512. https://doi.org/10.1002/jclp.22168

Ziemba, S. J., Bradley, N. S., Landry, L. A., Roth, C. H., Porter, L. S., \& Cuyler, R. N. (2014). Posttraumatic stress disorder treatment for Operation Enduring Freedom/Operation Iraqi Freedom combat veterans through a civilian community-based telemedicine network. Telemedicine and e-Health, 20(5), 446-450. https://doi.org/10.1089/tmj.2013.0312 
Table 1

Telehealth Satisfaction Questionnaire Results - Child Report

\begin{tabular}{|c|c|c|c|c|c|}
\hline \multirow[b]{2}{*}{ Question } & \multicolumn{4}{|c|}{ Number of respondents by Likert scale score } & \multirow{2}{*}{$\begin{array}{l}\text { Percentage of } \\
\text { respondents } \\
\text { giving ratings } \\
\text { of } 3 \text { or } 4\end{array}$} \\
\hline & $\begin{array}{c}\text { Disagree } \\
\text { a lot } \\
(1) \\
\end{array}$ & $\begin{array}{c}\text { Disagree } \\
\text { a little } \\
(2) \\
\end{array}$ & $\begin{array}{c}\text { Agree a } \\
\text { little } \\
(3)\end{array}$ & $\begin{array}{c}\text { Agree a } \\
\text { lot } \\
(4) \\
\end{array}$ & \\
\hline I liked the telehealth therapy using the computer / tablet. & 0 & 1 & 7 & 36 & $97.7 \%$ \\
\hline $\begin{array}{l}\text { I was comfortable interacting with my therapist on the computer / } \\
\text { tablet. }\end{array}$ & 0 & 0 & 4 & 40 & $100.0 \%$ \\
\hline My therapist cared about me as a person. & 0 & 0 & 2 & 42 & $100.0 \%$ \\
\hline $\begin{array}{l}\text { I felt as connected to my therapist as I would if therapy had been } \\
\text { face-to-face (in person). }\end{array}$ & 0 & 0 & 12 & 32 & $100.0 \%$ \\
\hline I felt that my therapist respected my values and beliefs. & 0 & 0 & 3 & 41 & $100.0 \%$ \\
\hline I felt my information was kept private during telehealth sessions. & 0 & 0 & 6 & 38 & $100.0 \%$ \\
\hline It was convenient to have my appointments at school or home. & 0 & 1 & 5 & 38 & $97.7 \%$ \\
\hline The telehealth equipment was easy to use. & 0 & 0 & 6 & 38 & $100.0 \%$ \\
\hline Receiving therapy with telehealth helped me to feel better. & 0 & 1 & 3 & 40 & $97.7 \%$ \\
\hline I think telehealth is as good as seeing a therapist in person. & 1 & 2 & 4 & 37 & $93.2 \%$ \\
\hline If I needed therapy again, I would use telehealth. & 0 & 2 & 2 & 40 & $95.5 \%$ \\
\hline $\begin{array}{l}\text { I would recommend telehealth to family or friends who need } \\
\text { therapy. }\end{array}$ & 0 & 1 & 6 & 37 & $97.7 \%$ \\
\hline I would rather use telehealth therapy than travel to [clinic name]. & 0 & 2 & 6 & 36 & $95.5 \%$ \\
\hline Total number of responses in each category & 1 & 10 & 66 & 495 & \\
\hline Proportion of total responses (\%) & $<0.1 \%$ & $1.7 \%$ & $11.5 \%$ & $86.5 \%$ & $98.1 \%$ \\
\hline
\end{tabular}


Table 2

Telehealth Satisfaction Questionnaire Results - Caregiver Report

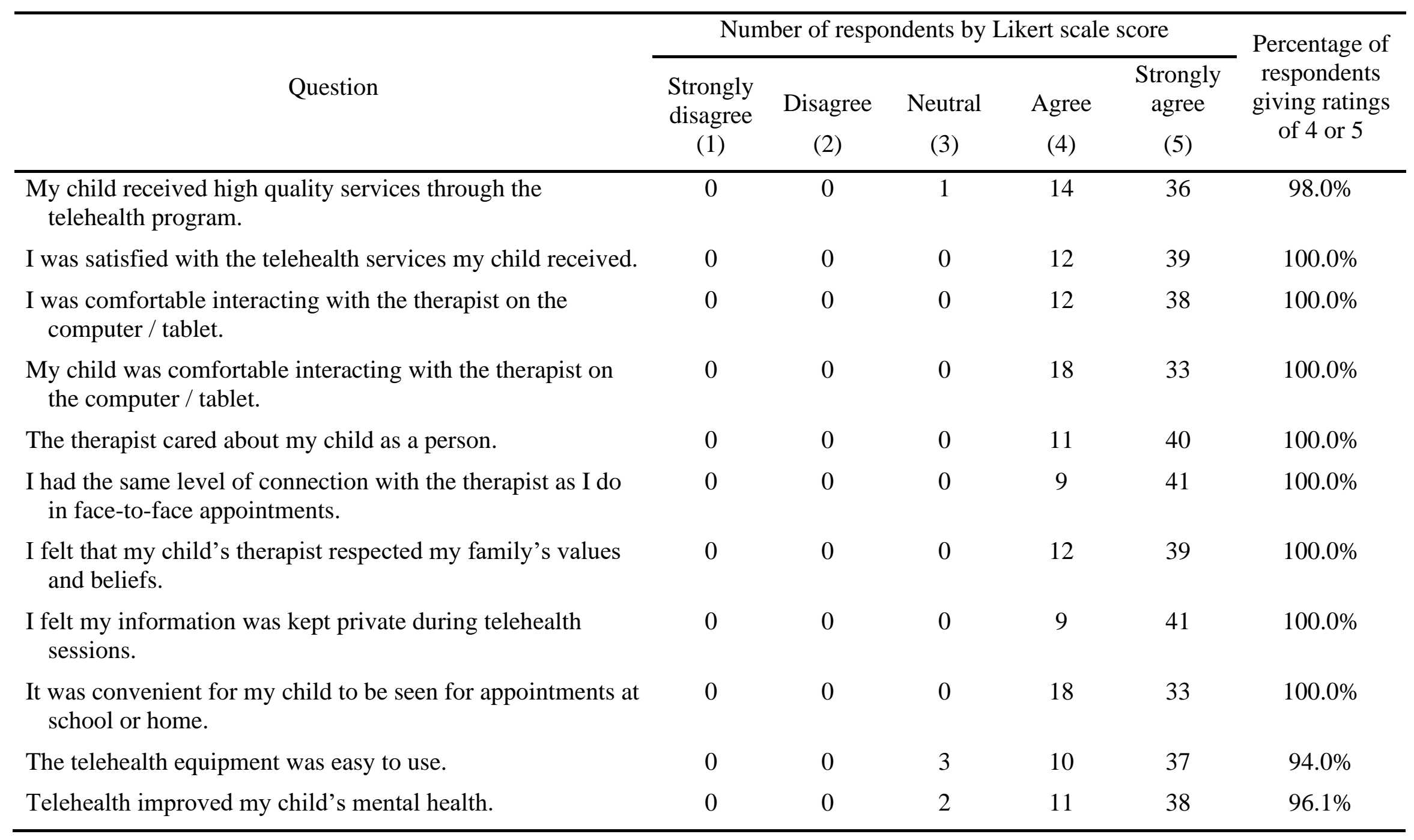




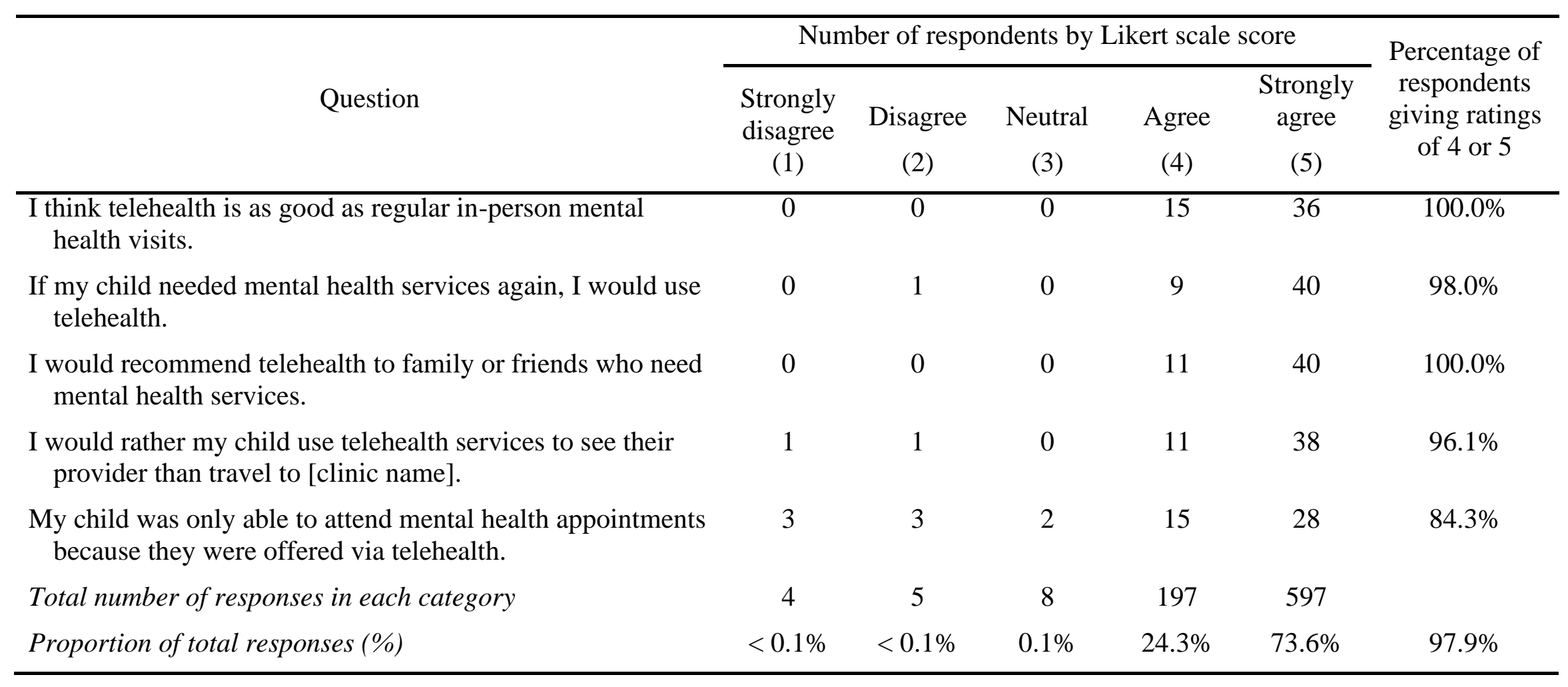




\section{Appendix A}

Date completed:

Time completed:

Survey administered by:

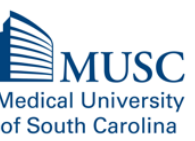

\section{Telehealth Satisfaction Questionnaire Parent/Caregiver Report}

\section{Authors: Regan W. Stewart, Bianca T. Villalobos, Rosaura Orengo-Aguayo Medical University of South Carolina}

Patient's Name:

Caregiver's Name:

Phone Number:

Clinician Name:

Telehealth equipment used (check all that apply): $\quad \square$ Tablet $\quad \square$ Computer

Location of Services (check all that apply): $\square$ Home $\quad \square$ School

$\square$ Primary Care $\quad \square$ Other:

Hello, my name is (your name) and I am calling from (clinic/program) to follow up about the mental health services that your child received through our telehealth program. Your child worked with (therapist name) at (locations of services). By participating in this survey, you can help us improve the program for others. We are interested in your honest opinions, whether they are positive or negative. We also welcome your comments and suggestions. Would you be willing to answer a few questions? It will only take about 5 minutes (wait for a response here). Thank you very much; we really appreciate your help. For most of the questions, I will read the question and give you several responses to choose from. You are going to tell me how much you agree with the sentence I read.

1. My child received high quality services through the telehealth program.

$\square$ Strongly Agree $\quad \square$ Agree $\quad \square$ Neutral $\quad \square$ Disagree $\quad \square$ Strongly Disagree

2. I was satisfied with the telehealth services my child received.
$\square$ Strongly Agree
Agree
$\square$ Neutral
Disagree
$\square$ Strongly Disagree

3. I was comfortable interacting with the therapist on the computer/tablet.
Strongly Agree
Agree
$\square$ Neutral
Disagree
Strongly Disagree

4. My child was comfortable interacting with the therapist on the computer/tablet. 
$\square$ Strongly Agree $\quad \square$ Agree $\quad \square$ Neutral $\quad \square$ Disagree $\quad \square$ Strongly Disagree

5. The therapist cared about my child as a person.
Strongly Agree
Agree
$\square$ Neutra
Disagree
$\square$ Strongly Disagree

6. I had the same level of connection with the therapist as I do in face-to-face appointments.
$\square$ Strongly Agree
Agree
$\square$ Neutral
Disagree
$\square$ Strongly Disagree

7. I felt that my child's therapist respected my family's values and beliefs.
Strongly Agree
Agree
$\square$ Neutral
Disagree
Strongly Disagree

8. I felt my information was kept private during telehealth sessions.

$\square$ Strongly Agree $\quad \square$ Agree $\quad \square$ Neutral $\quad \square$ Disagree $\square$ Strongly Disagree

9. It was convenient for my child to be seen for appointments at school or home.
$\square$ Strongly Agree
Agree
$\square$ Neutral
Disagree
$\square$ Strongly Disagree

10. The telehealth equipment was easy to use.

$\square$ Strongly Agree $\quad \square$ Agree $\quad \square$ Neutral $\quad \square$ Disagree $\quad \square$ Strongly Disagree

11. Telehealth improved my child's mental health.

$\square$ Strongly Agree $\quad \square$ Agree $\quad \square$ Neutral $\quad \square$ Disagree $\quad \square$ Strongly Disagree

12. I think telehealth is as good as regular in-person mental health visits.
Strongly Agree
Agree
$\square$ Neutral
Disagree
Strongly Disagree

13. If my child needed mental health services again, I would use telehealth.
$\square$ Strongly Agree
Agree
$\square$ Neutral
Disagree
$\square$ Strongly Disagree

14. I would recommend telehealth to family or friends who need mental health services.
Strongly Agree
Agree
$\square$ Neutra
Disagree
Strongly Disagree

15. I would rather my child use telehealth services to see their provider than travel to MUSC.
Strongly Agree
Agree
Neutral
Disagree
Strongly Disagree 
16. My child was only able to attend mental health appointments because they were offered via telehealth.
$\square$ Strongly Agree
Agree
$\square$ Neutral
Disagree
Strongly Disagree

17. Did you experience barriers that prevented your child from seeing a clinician face-to-face in an office (for example, difficulty with transportation, distance to services, work schedule, need for childcare)?

$\mathrm{NO} \rightarrow$ Go to question \#18.

YES $\rightarrow$ Follow-up with statement below:

There are many reasons why people are unable to get mental health services in person and that might have caused you to use telehealth services instead of going to an office. I'm going to read each one. Tell me if any of these was a barrier to your child seeing a clinician face-to-face in an office (check all that apply).

\section{Lack of transportation}

Need for childcare

Work schedule/requesting time off work

No insurance

Cost of services

Distance to mental health services clinic

Didn't know where to go or what was available where I live

Being concerned about what others would think about seeking services

Other:

18. If your child had to go to an office for the same types of services that they received through telehealth, how many miles (or minutes) would you have to drive to get to the closest officebased mental health services? miles / minutes

19. Were you comfortable using telehealth services at the time of the first visit?

$\square$ YES $\rightarrow$ Go to question \#20.

$\square \mathrm{NO} \rightarrow$ Follow-up with questions \#a and \#b below:

a. What were your concerns?

b. Did you become more comfortable over time? 
$\square \mathrm{NO} \rightarrow$ Go to question \#20.

$\square$ YES $\rightarrow$ Follow-up with the question \#c below:

c. What changed?

20. What was the best part about the telehealth program?

21. What would you like to see added, changed, or removed from the telehealth program?

22. Do you have any additional comments or suggestions?

Thank you for helping us evaluate the services that this program provides. It will greatly assist us in providing care to others who may need these services in the future. 
Appendix B

Date completed:

Time completed:

Survey administered by:

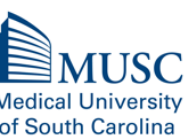

Telehealth Satisfaction Questionnaire

Child Report (for children ages 11+)

\section{Authors: Regan W. Stewart, Bianca T. Villalobos, Rosaura Orengo-Aguayo Medical University of South Carolina}

Patient's Name:

Caregiver's Name:

Phone Number:

Clinician Name:

Telehealth equipment used (check all that apply): $\quad \square$ Tablet $\square$ Computer

Location of Services (check all that apply): $\square$ Home $\square$ School

$\square$ Primary Care

Other:

$\mathrm{Hi}$, (patient name). This is (your name) from (clinic/program name). I just talked with your (mom/dad/etc.) about therapy that you did with (therapist name) through the computer or tablet at (location of services). I'd like to ask you a few questions about what you thought about the telehealth therapy. Would you be willing to answer a few questions? It will only take a few minutes (wait for a response here). Thanks so much; we really appreciate your help. For most of the questions, I will read the question and give you several responses to choose from. You are going to tell me how much you agree with the sentence I read.

1. I liked the telehealth therapy using the computer/tablet.
Agree a lot
Agree a little
Disagree a little
Disagree a lot

2. I was comfortable interacting with my therapist on the computer/tablet.
Agree a lot
Agree a little
$\square$ Disagree a little
$\square$ Disagree a lot

3. My therapist cared about me as a person.
Agree a lot
Agree a little
$\square$ Disagree a little
Disagree a lot

4. I felt as connected to my therapist as I would if therapy had been face-to-face (in person).
Agree a lot
Agree a little
$\square$ Disagree a little
Disagree a lot 
5. I felt that my therapist respected my values and beliefs.
$\square$ Agree a lot
Agree a little
Disagree a little
Disagree a lot

6. I felt my information was kept private during telehealth sessions.
Agree a lot
Agree a little
$\square$ Disagree a little
Disagree a lot

7. It was convenient to have my appointments at school or home.
Agree a lot
Agree a little
Disagree a little
Disagree a lot

8. The telehealth equipment was easy to use.
Agree a lot
Agree a little
Disagree a little
Disagree a lot

9. Receiving therapy with telehealth helped me to feel better.
Agree a lot
Agree a little
$\square$ Disagree a little
Disagree a lot

10. I think telehealth is as good as seeing a therapist in person.
Agree a lot
$\square$ Agree a little
$\square$ Disagree a little
Disagree a lot

11. If I needed therapy again, I would use telehealth.
Agree a lot
Agree a little
$\square$ Disagree a little
Disagree a lot

12. I would recommend telehealth to family or friends who need therapy.
Agree a lot
Agree a little
$\square$ Disagree a little
$\square$ Disagree a lot

13. I would rather use telehealth therapy than travel to MUSC.

$\square$ Agree a lot $\square$ Agree a little $\quad \square$ Disagree a little $\square$ Disagree a lot

14. Were you comfortable using the computer/tablet from the beginning of therapy?

$\square \mathrm{YES} \rightarrow$ Go to question \#15.

$\square \mathrm{NO} \rightarrow$ Follow-up with questions \#a and \#b:

d. What were your concerns?

e. Did you get more comfortable over time? 
$\square \mathrm{NO} \rightarrow$ Go to question \#15.

$\square$ YES $\rightarrow$ Follow-up with question \#c below:

f. What changed?

15. What was the best part about the telehealth therapy?

16. What would you like to see added, changed, or removed from the telehealth therapy?

17. Is there anything else you would like me to know about your experience with the telehealth therapy?

Thank you for answering these questions. Your answers will help us in making our program better. 